Интернет-журнал «Науковедение» ISSN 2223-5167 https://naukovedenie.ru/

Том 9, №5 (2017) https://naukovedenie.ru/vol9-5.php

URL статьи: https://naukovedenie.ru/PDF/108TVN517.pdf

DOI: 10.15862/108TVN517 (http://dx.doi.org/10.15862/108TVN517)

Статья опубликована 13.12.2017

Ссылка для цитирования этой статьи:

Казарян Р.Р., Комаров Н.М., Чулков В.О., Казарян Д.Р. Изменчивость и адаптивная норма в системе «человектехника-среда, ЧТС» // Интернет-журнал «НАУКОВЕДЕНИЕ» Том 9, №5 (2017)

https://naukovedenie.ru/PDF/108TVN517.pdf (доступ свободный). Загл. с экрана. Яз. рус., англ.

DOI: $10.15862 / 108 \mathrm{TVN} 517$

\title{
УДК 643.01:338.2
}

Казарян Рубен Рафаелович

ФГБОУ ВО «Национальный исследовательский «Московский государственный строительный университет», Россия, Москва ${ }^{1}$ Профессор кафедры «Технология и организация строительного производства» Доктор технических наук E-mail: kazarian@mail.ru

\section{Комаров Николай Михайлович}

ФГУП «Центральный научно-исследовательский институт «ЦЕНТР», Россия, Москва 2 Научный консультант, доктор экономических наук, профессор E-mail: nikolai_komarov@mail.ru

Чулков Виталий Олегович ФГБОУ ВО «Национальный исследовательский «Московский государственный строительный университет», Россия, Москва Профессор кафедры «Технология и организация строительного производства» Доктор технических наук E-mail: vitolch@gmail.com

Казарян Дора Рубеновна ФГБОУ ВО «Московский государственный университет имени М.В. Ломоносова», Россия, Москва ${ }^{3}$ Социологический факультет, кафедра «Социологии коммуникативных систем» Магистр E-mail: cazarian.dor@yandex.ru

\section{Изменчивость и адаптивная норма в системе «человек-техника-среда, ЧТС»}

Аннотация. Различают наследственную (мутационную и комбинативную) и ненаследственную (модификационную или фенотипическую) изменчивость в организме человека. Модификационная изменчивость возникает как результат взаимодействия с окружающей внешней средой, на воздействия факторов которой разные люди реагируют поразному. Существует понятие «норма реакции» как предел модификационной изменчивости, в рамках возможностей конкретного человека. В большинстве случаев модификация представляет собой полезную приспособительную реакцию организма, т. е. носит адаптивный

\footnotetext{
${ }^{1}$ Россия, Москва, Ярославское шоссе, 26

2 Россия, Москва, ул. Садово-Кудринская, 11, строение 1

${ }^{3}$ Россия, Москва, Ленинские горы, МГУ, 1, строение 33
} 
характер (адаптивная норма). Адаптивный характер обычно присущ модификациям, которые вызваны воздействием типичных факторов конкретной среды. Если организм попадает под действие необычного фактора (например, воздействие химических веществ и облучения) или же резко увеличивается интенсивность воздействия обычного фактора, то могут возникать неадаптивные модификации (морфозы), часто проявляющие себя как уродства. Чем шире норма реакции, тем выше адаптационный потенциал человека. В отличие от мутаций, модификации обладают разной степенью стойкости. Многие модификации исчезают вскоре после того, как перестает действовать вызвавший их фактор. Другие могут сохраняться у человека на протяжении всей его жизни. В статье рассмотрена возможность использования достижений молекулярной и физико-химической биологии в комплексном изучении проблемы нормального функционирования организма человека в условиях повышенно-напряженной деятельности в строительстве. Авторы считают, что крайне необходимы исследования закономерностей изменения состояния адаптивной нормы организма человека на уровне генетического аппарата, с использованием новейших разработок нанотехнологий. Рассмотрена возможность энзиматической регуляции альтернативных трансгипофизарному механизму путей регуляции. Предложена концепция нормы живой системы как иерархией структуры и функционального контроля. Этот иерархический принцип объединяет уровни атомных и молекулярных взаимодействий, реализующихся на ничтожно малых расстояниях, до уровня взаимодействий в человеческом обществе, которые осуществляются на очень больших расстояниях, и благодаря которым общество представляет собой организованную систему.

Ключевые слова: наследственная и ненаследственная изменчивость; адаптивная норма; нанотехнологии; энзиматическая регуляция; трансгипофизарный механизм; атомные и молекулярные взаимодействия; норма реакций; система «человек-техника-среда, ЧТС»; мутация; гомеостазис; нуклеиновые кислоты; белки; стресс; дистресс

Существенной характеристикой современного этапа развития социума является исключительно напряженный ритм жизни, являющийся следствием использования бесконечного разнообразия техники, высокоинтенсифицированных производственных процессов, необходимости ежедневно обрабатывать огромное количество всевозможной информации, активного участия в разных сферах жизнедеятельности (Техника - продукт мышиления человека, материально реализованный в продуктивной деятельности человека как средство обеспечения его потребности; искусственная среда обитания человека; компонент системы «человек-техника-среда»- ЧТС).

Эмоциональное напряжение входит составной частью в сложный комплекс адаптации, как приспособительной реакции человека к внешней среде. Оно создает оптимальный уровень психических, психофизиологических и биохимических процессов, чем способствует наилучшему использованию ресурсов организма в соответствии с требованиями ситуации. Вместе с тем, механизм эмоциональной стимуляции имеет предел, превышение которого сопровождает дезинтеграция основных жизненных процессов с нарушением психической деятельности и поведения человека. Превышение этого предела служит причиной перехода стресса в дистресс. Определение этого состояния важно ещё и потому, что длительная напряженность может неблагоприятно повлиять на состояние здоровья человека. Вследствие нервного перенапряжения функционирование организма человека может существенно отклониться от нормального с последующими сердечно-сосудистыми нарушениями, проявлением гипертонии, язвенной болезни, неврозов, психозов и других патологических (в большинстве случаев необратимых) изменений.

Исследование надежности деятельности человека будет носить более эффективный характер при его всестороннем комплексном изучении, затрагивающем все уровни 
взаимодействия человека и среды. В центре внимания современной психологии - мотивация поведения человека. Известно, что в зависимости от цели деятельности (мотива) изменяется активность человека и, тем самым, изменяется надежность его функционирования в нормированной деятельности. Это особенно часто наблюдают при стрессовых состояниях организма человека.

Современная молекулярная и физико-химическая биология располагают развитыми представлениями о понятиях «норма реакций» и «адаптивная норма», а физико-химическая биология доказала факт вовлечения генетического аппарата в адаптационные переустройства высших организмов. По-видимому, это открывает возможность, с разработкой новых, высокочувствительных методов исследования, проследить закономерности изменения на уровне генетического аппарата перехода организма человека на новый уровень нормального функционирования - «адаптивную норму».

Самое удивительное в современной физико-химической биологии - это то, что она не замедляет стремительный темп своего развития. Благодаря появлению тонких и точных физических и химических методов исследования и с их помощью которым ученым удалось проникнуть в самые глубокие недра клетки и обнаружить новые факты при изучении таких основных жизненных явлений, как размножение, рост, изменчивость, развитие, наследственность. Ключевые позиции во всех этих явлениях занимают молекулы двух классов важнейших биополимеров - нуклеиновых кислот и белков. Именно они составляют главную материальную основу живого организма человека и осуществляют её главнейшие функции в процессах жизнедеятельности. Однако нуклеиновым кислотам, являющимся материальной основой наследственности, принадлежит исключительно важная роль - способность к самоповторению.

Любой физиологический параметр (как и биохимические изменения) не может быть надежным показателем состояния предельной напряженности организма человека. Соматические изменения в большей или меньшей мере подвержены произвольной регулировке. Психические категории, к сожалению, плохо поддаются непосредственному объективному контролю, а применяемые в таких случаях опосредованные методы вносят элемент субъективности и не учитывают возможность произвольных влияний. Формы поведения, являющиеся отражением внутренних изменений в организме, также до некоторой степени поддаются произвольной регулировке. Необходимо признать, что практически не существует достаточно надежного коррелята напряженности.

Необходимо найти адекватный и надежный индикатор стрессового состояния с тем, чтобы иметь возможность в реальном масштабе времени влиять на состояние и деятельность человека, работающего в условиях повышенной напряженности. Таким коррелятом оценки состояния напряженности, по нашему мнению, в недалеком будущем может стать молекулярно-биологическая оценка состояния генетического аппарата, которая обеспечит гармоничную взаимосвязь разных изменений смежных уровней организации человека: психического, психофизиологического, физиологического и биохимического, - объяснив взаимоотношения многоуровневых систем организма со средой и отражение этих уровней в психике.

В этой связи исследование проблемы адаптивных возможностей человека приобретает особую значимость, поскольку морфологические и физиологические особенности человека, сформировавшиеся в течение длительного периода эволюции, исчисляемого миллионами лет, не могут изменяться с такой же быстротой, с какой изменяются технологические процессы и окружающая среда. Несоответствие во времени между этими процессами может привести к возникновению своего рода «ножниц» между адаптационными возможностями человека, 
обусловленными его биологической природой, и изменениями окружающей среды, что проявляется в разных патологических состояниях.

Объективная сложность и противоречивость определения нормы в биологии, медицине и психологии связаны прежде всего с тем, что нормальное для одной формы организации живого или научно-практического направления деятельности для одного структурного компонента системы может быть аномальным для других форм деятельности или компонентов систем. Наиболее ярко диалектический характер нормы и аномалий раскрыт в современной эволюционной теории. Установлено, что мутации, как правило, - нарушения нормы, ибо они дезорганизуют сложившиеся корреляции организма. В то же время, мутации оказываются совершенно необходимыми для выживания организма в изменившихся условиях среды.

Это диалектическое противоречие нормы и аномалии является фундаментальным противоречием для поддержания и развития жизни, имманентно присущим всякой развивающейся системе. Оно может разрешаться трояко:

- мутации включаются в сложившуюся (но лабильную) норму, фиксируя (стабилизируя) еe;

- мутации оказываются материалом для смены нормы на качественно новый уровень (адаптивную норму), что обеспечивает эволюционное преобразование нормы реакций организма человека;

- мутации могут настолько дезорганизовать сложившуюся адаптивную норму функционирования организма, что эволюционно выработанный гомеостазис не срабатывает - это приводит к разным патологическим нарушениям, а в пределе к вымиранию организма человека.

Следовательно, надежного функционирования организма при переходе нормы реакций в адаптивную норму достигают благодаря наличию аномалий и эволюционно выработанному гомеостазису. Накопление аномалий внутри адаптивной нормы, не нарушающее до определенного момента структуры генетического аппарата, порождает противоречие, которое приводит к «поиску» разрешения противоречия. Взаимодействие нормы и аномалий приводит к такому пороговому состоянию, когда организм должен «перешагнуть» свои рамки, - это и происходит при переходе в новую адаптивную норму. Единственное резкое нарушение адаптивной нормы, в основном, не может привести к различным патологическим изменениям (к истощению организма); требуется накопление мелких аномалий, способных перестроить глубинную структуру генетического аппарата.

В настоящее время вопрос о глобальном научном проекте уже давно назрел. Как сказано в Библии: есть время разбрасывать камни, есть время их собирать. Сегодня пришло такое время: наука обречена стать востребованной. Во всем мире пришел век нанотехнологий и цифровой экономики - это объективно новый уклад жизнедеятельности социума.

У человечества появилась альтернатива, по сути, «безотходного» производства - мы видим атомы, можем ими манипулировать и конструировать - что нам необходимо, создать новый материал с заданными свойствами. Это сложный, долгий путь, всех возможностей такого конструирования сегодня не представляет никто. И те страны, которые понимают эти вызовы и обладают соответствующим потенциалом, попадут в круг ведущих держав XXI века.

Сегодня мы пришли к новому этапу, разобравшись со строением белков, определив их сложную трехмерную пространственную структуру, изучив механизмы функционирования этих биологических молекул. Изучая на нанобиологическом уровне эти процессы, мы найдем более совершенный способ комплексной обработки информации и управления ею на уровне «адаптивной нормы» функционирования организма человека (наноуровень). 
Конечно, мы изучаем человека и пытаемся скопировать некоторые его свойства, уже сегодня пытаясь создавать детекторы на основе биологической самоорганизации. Но это всего лишь способ адаптировать нашу цивилизацию к живому миру, как он был задуман изначально. Сегодня уже совершенно очевидно, что возможности экономического роста на основе существующей модели индустриального мира полностью исчерпаны, потому что ресурс конечен.

Мир так дальше развиваться не может. У человечества не хватает достаточного ресурса «адаптивной нормы» нормального функционирования организма для противостояния, прежде всего, глобальному истощению энергетических ресурсов.

Именно поэтому нанопроекты по своей сути должны иметь изначально социальную направленность, ориентированную на нас с вами, обеспечивая моделирование и экспресс диагностику «адаптивной нормы» функционирования организма человека в условиях повышенно-напряженной деятельности.

\section{ЛИТЕРАТУРА}

1. Antropotechnics: norm in every living thing and artificial beings / Sudakov K. V., Chulcov V. O., Kazaryan R. R., Glazachev O. S., Dmitrieva N. V., Komarov N. M. M., SvR-ARGUS. - 2013.

2. Чулков В. О., Чулков Г. О., Казарян Р. Р. Картографирование патогенных зон в функциональной подсистеме инженерной диагностики жилища. - Мир науки. №1. -2013.

3. Нормотворчество в коммунальном хозяйстве и строительстве Кальгин А. А., Казарян Р. Р., Чулков В. О. / Под ред. В. О. Чулкова. - M., SvR-ARGUS. - 2012.

4. Чулков В. О., Казарян Р. Р., Гринберг И. Я. Нормология живых систем. В сборнике: Инновации в отраслях народного хозяйства, как фактор решения социально-экономических проблем современности. Сборник докладов и материалов 2-й Международной научно-практической конференции. Институт непрерывного образования, Московская государственная академия коммунального хозяйства и строительства, Центральный научноисследовательский институт экономики и управления в строительстве. 2012.

5. Лёвин Б. А., Казарян Р. Р., Чулков В. О. Инфография антропотехнического менеджмента: научное издание: в 3 т. / Под ред. В. О. Чулкова. - М.: ФГБУ ДПО «Учебно-методологический центр по образованию на железнодорожном транспорте», 2016. Том 1: Инфографическое моделирование в философии мыследеятельности. - 356 с., ил.

6. Лёвин Б. А., Казарян Р. Р., Чулков В. О. Инфография антропотехнического менеджмента: научное издание: в 3 т. / Под ред. В. О. Чулкова. - М.: ФГБУ ДПО «Учебно-методологический центр по образованию на железнодорожном транспорте», 2016. Том 2: Концепция опережающего формирования антропотехнической безопасности функционирования и качества жизни. -312 с., ил.

7. Лёвин Б. А., Казарян Р. Р., Чулков В. О. Инфография антропотехнического менеджмента: научное издание: в 3 т. / Под ред. В. О. Чулкова. - М.: ФГБУ ДПО «Учебно-методологический центр по образованию на железнодорожном 
транспорте», 2016. Том 3: Антропотехнический менеджмент как средство обеспечения сервисного обслуживания деятельности. - 264 с., ил.

8. Ретривация - инновационное направление в функциональной системе строительного переустройства / В. О. Чулков, О. Н. Кузина // Актуальные проблемы развития жилищно-коммунального хозяйства городов и населенных пунктов: Международный сборник научных трудов девятой Международной научно-практической конференции. - 30 мая - 6 июня 2010 г. - Москва-СофияКавала, 2010. - С. 439-443.

9. Qualities of documentation management chain (part 1) / A. A. Volkov, V. O. Chulkov, G. O. Chulkov, R. R. Kazaryan, O. N. Kyzina. - Advanced Materials Research Vols. 1065-1069 (2015) pp. 2401-2404. - C (2015) Trans Tech Publications, Switzerland. doi: 10.4028/www.scientific.net/AMR.1065-1069.2401.

10. Qualities of documentation management chain (part 2)/A. A. Volkov, V. O. Chulkov, G. O. Chulkov, R. R. Kazaryan, O. N. Kyzina. - Advanced Materials Research Vols. 1065-1069 (2015) pp. 2405-2408. - C (2015) Trans Tech Publications, Switzerland. doi: 10.4028/www.scientific.net/AMR.1065-1069.2405.

11. Qualities of documentation management chain (part 3)/A. A. Volkov, V. O. Chulkov, G. O. Chulkov, R. R. Kazaryan, O. N. Kyzina. - Advanced Materials Research Vols. 1065-1069 (2015) pp. 2405-2408. - C (2015) Trans Tech Publications, Switzerland. doi: 10.4028/www.scientific.net/AMR.1065-1069.2409.

12. К. Джини. - М.: Статистика (Новейшие зарубежные статистические исследования). - 2010. - Пер. изд.: Le Medi / Corrado Gini. - Milano. - 448 c.

13. Казарян Р. Р. Биологические проблемы понятия нормы в психологии. - Ереван: Изд-во «Айястан», 1985.

14. Селье Г. Г. Б. Стресс без дистресса. - Нью Йорк, изд-во Липпенкотт, 1974. Перевод на армянский Р. Р. Казарян. - Ереван: Изд-во «Айястан», 1983. 


\title{
Kazarian Ruben Rafaelovich \\ National research «Moscow state building university», Russia, Moscow \\ E-mail: kazarian@mail.ru
}

\author{
Komarov Nikolay Mikhailovich \\ Central research institute «CENTER», Russia, Moscow \\ E-mail: nikolai_komarov@mail.ru
}

Chulkov Vitaly Olegovich

National research «Moscow state building university», Russia, Moscow E-mail: vitolch@gmail.com

Cazarian Dora Rubenovna

Moscow state university named after M.V. Lomonosov, Russia, Moscow E-mail: cazarian.dor@yandex.ru

\section{Variability and adaptive norm in the system "man-technology-environment, MTE"}

\begin{abstract}
Distinguish between hereditary (mutational and combinative) and non-hereditary (modification or phenotypic) variability in the human body. Modificational variability arises as a result of interaction with the surrounding environment, the effects of factors which different people react differently. There is the concept of "reaction norm" as the limit of modification variability, within the capabilities of a particular person. In most cases, modification is a useful adaptive response of the organism, is adaptive in nature (adaptive norm). Adaptive nature is usually inherent in modifications that are caused by the impact of typical factors of a particular environment. If the organism falls under the influence of an unusual factor (for example, exposure to chemicals and radiation), or the intensity of the usual factor is sharply increased, then non-adaptive modifications (morphoses) often manifest themselves as deformities. The wider the norm of the reaction, the higher the human adaptation potential. Unlike mutations, modifications have a different degree of resistance. Many modifications disappear soon after the factor that caused them ceases to function. Others can persist in a person throughout his life. The article considers the possibility of using the achievements of molecular and physico-chemical biology in a comprehensive study of the problem of the normal functioning of the human body in conditions of heightened activity in construction. The authors believe that it is extremely necessary to study the patterns of changes in the state of the adaptive norm of the human body at the level of the genetic apparatus, using the latest developments in nanotechnology. The possibility of enzymatic regulation of alternative ways of regulation by transhypophyseal mechanisms is considered. The concept of the norm of a living system as a hierarchy of structure and functional control is proposed. This hierarchical principle unites the levels of atomic and molecular interactions, realized at negligible distances, to the level of interactions in human society that take place at very great distances, and thanks to which society is an organized system.
\end{abstract}

Keywords: Hereditary and non-hereditary variability; adaptive norm; nanotechnologies; enzymatic regulation; transhypophysis mechanism; atomic and molecular interactions; the rate of reactions; the system "man-technology-environment, MTE"; mutation; homeostasis; nucleic acids; proteins; stress; distress

\section{REFERENCES}

1. Antropotechnics: norm in every living thing and artificial beings / Sudakov K. V., Chulcov V. O., Kazaryan R. R., Glazachev O. S., Dmitrieva N. V., Komarov N. M. M., SvR-ARGUS. - 2013. 
2. Chulkov V. O., Chulkov G. O., Kazaryan R. R. Mapping of pathogenic zones in the functional subsystem of engineering diagnostics of a dwelling. - The world of science. - No.1 - 2013.

3. Kalgin A. A., Kazaryan R. R., Chulkov V. O. Rulemaking in the municipal economy and construction / Ed. V. O. Chulkov. - M., SvR-ARGUS. - 2012.

4. Chulkov V. O., Kazaryan R. R., Grinberg I. Ya. Normology of living systems. In the collection: Innovations in the sectors of the national economy, as a factor in solving the social and economic problems of our time. Collection of reports and materials of the 2 nd International Scientific and Practical Conference. Institute of Continuing Education, Moscow State Academy of Public Utilities and Construction, Central Research Institute of Economics and Management in Construction. 2012.

5. Lyovin B. A., Kazaryan R. R., Chulkov V. O. Infographics of anthropotechnical management: a scientific publication: in 3 tons / Ed. V. O. Chulkov. - Moscow: FGBU DPO "Educational and Methodological Center for Education in Railway Transport", 2016. Volume 1: Infographic Modeling in the Philosophy of Thought-activity. - 356 pp., Ill.

6. Lyovin B. A., Kazaryan R. R., Chulkov V. O. Infographics of anthropotechnical management: a scientific publication: in 3 tons / Ed. V. O. Chulkov. - Moscow: FGBU DPO "Educational and Methodological Center for Education in Railway Transport", 2016. Volume 2: The concept of anticipatory formation of anthropotechnical safety of functioning and quality of life. $-312 \mathrm{pp}$., Ill.

7. Lyovin B. A., Kazaryan R. R., Chulkov V. O. Infographics of anthropotechnical management: a scientific publication: in 3 tons / Ed. V. O. Chulkova. - M.: FGBU DPO "Educational and Methodological Center for Education in Railway Transport", 2016. Volume 3: Anthropotechnical management as a means of providing service for the activities. -264 p., Ill.

8. Retrieval - an innovative direction in the functional system of building reconstruction / V. O. Chulkov, O. N. Kuzina // Actual problems of development of housing and communal services of cities and settlements: International collection of scientific papers of the Ninth International Scientific and Practical Conference. - 30 May - June 6, 2010 - Moscow-Sofia-Kavala, 2010. - P. 439-443.

9. Qualities of documentation management chain (part 1)/ A. A. Volkov, V. O. Chulkov, G. O. Chulkov, R. R. Kazaryan, O. N. Kyzina. - Advanced Materials Research Vols. 1065-1069 (2015) pp. 2401-2404. - C (2015) Trans Tech Publications, Switzerland. doi: 10.4028/www.scientific.net/AMR.1065-1069.2401.

10. Qualities of documentation management chain (part 2) / A. A. Volkov, V. O. Chulkov, G. O. Chulkov, R. R. Kazaryan, O. N. Kyzina. - Advanced Materials Research Vols. 1065-1069 (2015) pp. 2405-2408. - C (2015) Trans Tech Publications, Switzerland. doi: 10.4028/www.scientific.net/AMR.1065-1069.2405.

11. Qualities of documentation management chain (part 3)/ A. A. Volkov, V. O. Chulkov, G. O. Chulkov, R. R. Kazaryan, O. N. Kyzina. - Advanced Materials Research Vols. 1065-1069 (2015) pp. 2405-2408. - C (2015) Trans Tech Publications, Switzerland. doi: 10.4028/www.scientific.net/AMR.1065-1069.2409.

12. K. Gini. - Moscow: Statistics (Recent foreign statistical research). - 2010. - Пep. Ed.: Le Medi / Corrado Gini. - Milano. - 448 p.

13. Kazaryan R. R. Biological problems of the concept of norm in psychology. - Yerevan: "Hayastan" Publishing House, 1985.

14. Selye G. G. B. Stress without distress. - New York, Lippencott Publishing House, 1974. - Translation into Armenian by R. R. Kazarian. - Yerevan: "Hayastan" Publishing House, 1983. 